\title{
Modelling and Analysis of Hybrid Composite Joint Using Fem in Ansys
}

\author{
S.Venkateswarlu ${ }^{1}$, K.Rajasekhar ${ }^{2}$ \\ ${ }^{I}$ (Assistant Professor Senior, Department of Mechanical Engineering SKIT, Srikalahasthi, \\ ${ }^{2}$ (P.G Student, Department of Mechanical Engineering SKIT, Srikalahasthi,
}

\begin{abstract}
Composite materials are widely used in the various Fields. Due to the high strength they are widely used in the low weight constructions and also used as a suitable alternative to metals. In various applications and also for joining various composite parts together, they are fastened together using adhesives or Mechanical fasteners. Modeling and static analysis of 3-D Models of joints such as bonded, riveted and hybrid. The results were found in terms of vonmises stress, shear stress, and normal stress for stress distribution. ANSYS FEA tool has been used for stress distribution characteristics of various configurations of double riveted single lap joint with three joining methods namely bonded, riveted and hybrid the present study deals with the analysis of single lap joint subjected to the given tensile load and the stress distribution in the members under various design conditions are found.
\end{abstract}

Keywords: composite materials, FEA-Ansys, joint strength, bonded, riveted, hybrid.

\section{Introduction}

Nowadays the composite materials like plastics reinforced with carbonfibres (CFRP), glassfibres (GFRP), and aramidfibres (AFRP) are widely used in various industries such as automotive, chemical, electrical industry, aircraft and even in cryogenics. Due to its superior properties, composites have been one of the materials used for repairing the existing structures in various applications and also for joining composite parts together, using adhesives or mechanical fasteners nowadays, a new method called hybrid joint is also being employed where a combination of both adhesive and mechanical fasteners are used. In the present project, an attempt is made to analyze the stress distribution in $3 \mathrm{D}$ models of three configurations of double riveted single lap joint namely bonded, riveted, hybrid. A major advantage of adhesive bonds with fastener may be designed and made in such a way that they can be stronger than the ultimate strength of many metals and it is broadly used in the aircrafts.

\section{Objective}

In this attempt three joints were modeled using pro-e and analysis is done by Ansys work bench. The stresses such as vonmises, shear and normal stresses were found.

\section{Materials And Methods}

Material of GFRP (glass fiber reinforced plastic) composite with Modeling and static analysis of 3-D Models of the joints (bonded, riveted and hybrid) were carried Out using pro-E (creo parametric) modeling and ANSYS FEA software. The results were interpreted in terms of vonmises stress, shear stress, normal stress.

Noah m. Salih et al [2012]., Hybrid (bonded/bolted) composite single-lap joints and its load transfer analysis in hybrid joints is complicated because of differences among alternate load path stiffness in hybrid composite single-lap joints including the effects of bolt-hole contact and non-linear material behavior. The effect of relevant joint design parameters on the load transferred by the bolt have been investigated through a finite element parameter study. [1] Ch.Aswinikumar et al [2012]., Analysis of adhesively bonded double lap joint in laminated FRP composites subjected to longitudinal loading the present investigation deals with the static analysis of adhesively bonded double lap joint in laminated FRP composites using the three-dimensional theory of elasticity based finite element method. Shear stresses at the interfaces of the adhered and adhesive are calculated for different adhesive thicknesses. [2] Vincent Caccese et al [2004]. Detection of bolt load loss in hybrid composite/metal bolted connections accordingly the focus of this research is on experimentally quantifying changes in bolt load of composite/metal hybrid connections. A proof-of-concept model was created consisting of a fiber reinforced composite panel bolted to a steel frame. A piezoelectric actuator bonded to the center of the composite panel was used to provide controlled vibration input. [3] W. Hufenbach et al [2006].,Optimization of the rivet joints of the CFRP composite material and aluminum alloy the modeled static tensile strength test carried out for the plates from CFRP and from the 6061 aluminum alloy joined with the steel rivet. A computer simulation was carried out with an IDEAS software package employing the FEM. Simulations using the mesh with a bigger number of FEM elements do not yield better accuracy of calculations and do not 
improve convergence with the results of laboratory Experiments. Results obtained for the mesh with 4 and 5 FEM elements are the closest to the results of laboratory experiments, which is confirmed by the strain plot. [4].M.A McCarthy et al[2012]A three dimensional finite element analysis on the effects of bolt hole clearance[5].[6]S.lokesh et al [2013]A parametric study to compare the performance of hybrid joint with variying adherent thickness,adhesive thickness and overlap length the strength can be found by using universal testing machine.

\subsection{Finite Element Analysis Of Composite Joints}

ASTM specimens of size with geometry are shown below in the table1:

\begin{tabular}{|c|c|}
\hline Width of plate & $22.5 \mathrm{~mm}$ \\
\hline Length of plate & $100 \mathrm{~mm}$ \\
\hline Thickness of plates & $2.5 \mathrm{~mm}$ \\
\hline Plate overlaps & $20 \mathrm{~mm}$ \\
\hline Diameter of the holes in plates & $4 \mathrm{~mm}$ \\
\hline Diameter of the rivet head & $6 \mathrm{~mm}$ \\
\hline Height of rivet head & $4 \mathrm{~mm}$ \\
\hline Total rivet height & $13 \mathrm{~mm}$ \\
\hline
\end{tabular}

Pro/ENGINEER is a feature-based, parametric solid modeling system with many extended design and manufacturing applications. Pro-E (creo-parametric) was used in the model the commercial FEA software ANSYS work bench has been used to analyze the models. The adhesive layer between the laminates of thickness $0.4 \mathrm{~mm}$ an aluminum rivet was used for mechanical fastening. The GFRP material is used for analysis and stress values are found. One end of the adherend was constrained from $\mathrm{x}, \mathrm{y}, \mathrm{z}$ translations. While the other end the load of $5000 \mathrm{~N}$ was applied to this end towards the positive $\mathrm{x}$-direction. The pro-e models of bonded, riveted and hybrid joints are shown in the figure from 1-3 and Meshed models of bonded, riveted and hybrid joints are shown in the fig 4-6. Bonded joints were developed by using hexagonal element. Adherent and adhesive were glued together and finer mesh was used in the design.

Element type: hexagonal

Table: 2

\begin{tabular}{|c|c|c|}
\hline Bonded joint: & $\begin{array}{c}\text { Number of nodes } \\
9979\end{array}$ & $\begin{array}{c}\text { Number of elements } \\
1320\end{array}$ \\
\hline Riveted joint & 10526 & 2013 \\
\hline Hybrid joint & 11705 & 2147 \\
\hline
\end{tabular}

Table: 3

\begin{tabular}{|l|l|l|l|}
\hline Type of material & $\begin{array}{l}\text { Young's modulus } \\
\text { In Gpa }\end{array}$ & $\begin{array}{l}\text { Density } \\
\mathrm{Kg} / \mathrm{mm}^{3}\end{array}$ & Poisson ratio \\
\hline GFRP & 28 & $1.9 \times 10^{-6}$ & 0.26 \\
\hline aluminium & 70 & $2.71 \times 10^{-6}$ & 0.33 \\
\hline epoxy & 4 & $1.08 \times 10^{-6}$ & 0.4 \\
\hline
\end{tabular}

Diameter of the rivet $\mathrm{d}=2 \mathrm{t}$

\section{Analytical Calculation:}

$\mathrm{d}=2 \times 2.5=5 \mathrm{~mm}$

Pitch of rivets $=4 \mathrm{~d}$

$\mathrm{P}=4 \times 5=10 \mathrm{~mm}$

Margin $m=1.5 \mathrm{~d}=1.5 \times 4=6 \mathrm{~mm}$

Transverse pitch $=P_{t}=2 d=10 \mathrm{~mm}$

Shear stress for the riveted joint

$$
\begin{aligned}
\tau & =(0.7) \times \sigma t(1) \\
& =0.7 \times 365 \\
& =255.5 \mathrm{~N} / \mathrm{mm}^{2} \\
\tau & =\mathrm{F} /(\mathrm{txl})(2) \\
& =5000 /(2 \times 2 \times 22.5) \\
& =55.5 \mathrm{~N} / \mathrm{mm}^{2}
\end{aligned}
$$




\section{Figures And Tables}

The model of bonded, riveted, hybrid joints is shown in figure1-3
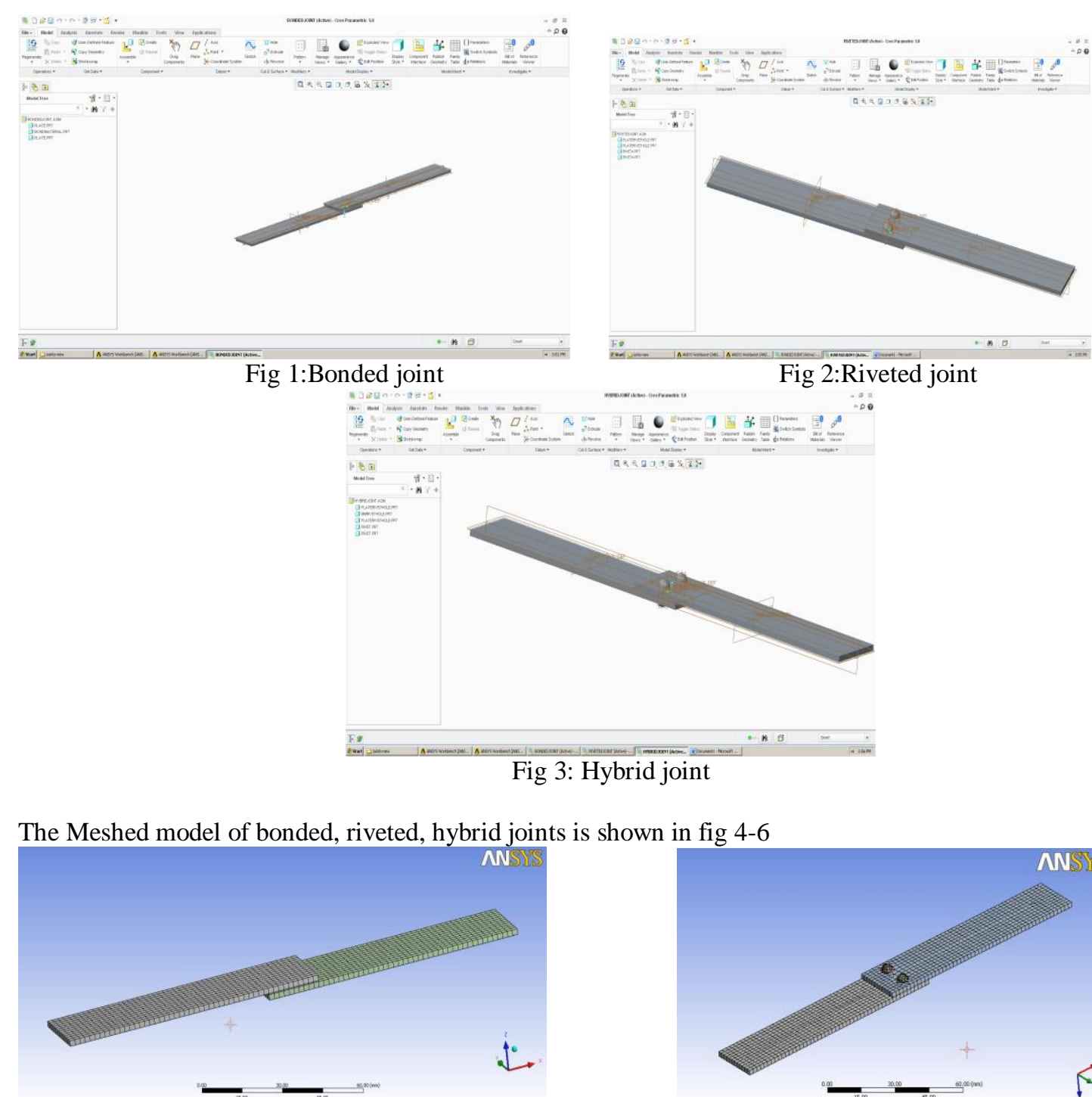

Fig 4: Bonded

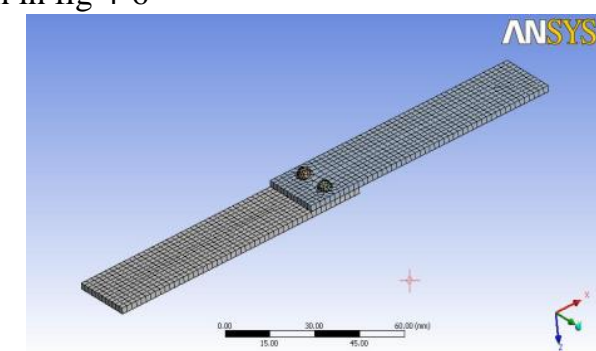

Fig 5: Riveted

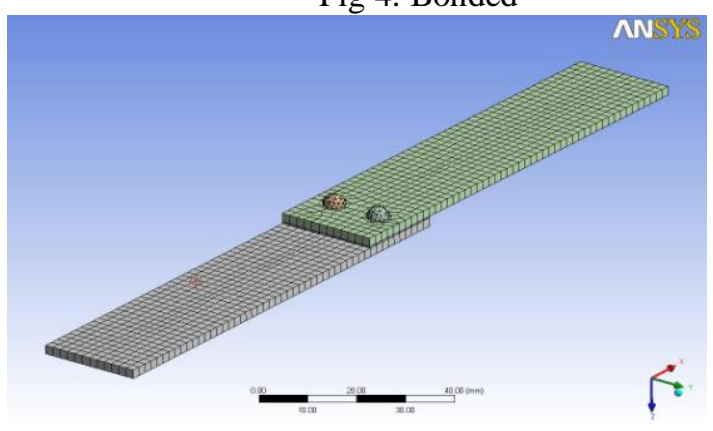

Fig 6: Hybrid

\subsection{Bonded joints:}

The maximum value of vonmises stress is $416 \mathrm{~N} / \mathrm{mm}^{2}$ and the minimum value of stress is 0.00062413 $\mathrm{N} / \mathrm{mm}^{2}$. The maximum value of shear stress in bonded joint with GFRP was found to be $60.569 \mathrm{~N} / \mathrm{mm}^{2}$ it was located at the bonded region. The minimum value of shear stress in GFRP was found to be- $160.57 \mathrm{~N} / \mathrm{mm}^{2}$ it was located at the end of the plate. The images of analysis result of vonmises, shear stress and normal stress of bonded joint are given in the fig 7-11. 


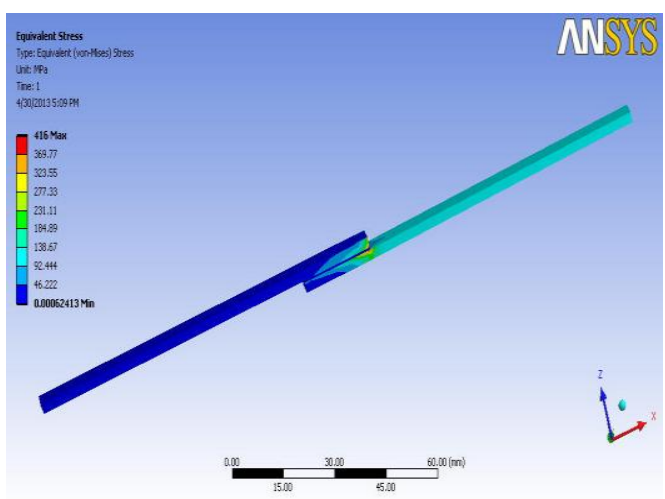

Fig7: Vonmises stress of bonded joint

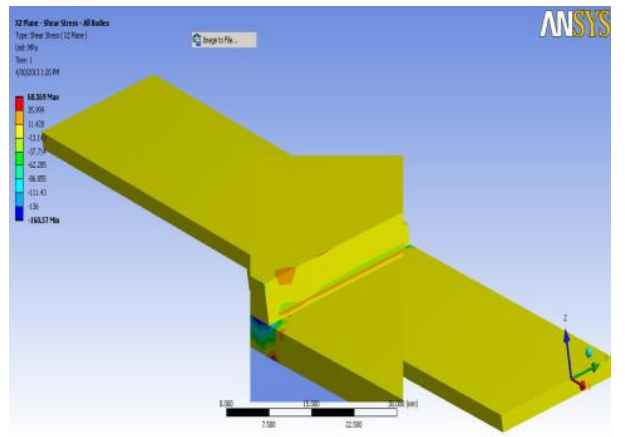

Fig 8: shear stress

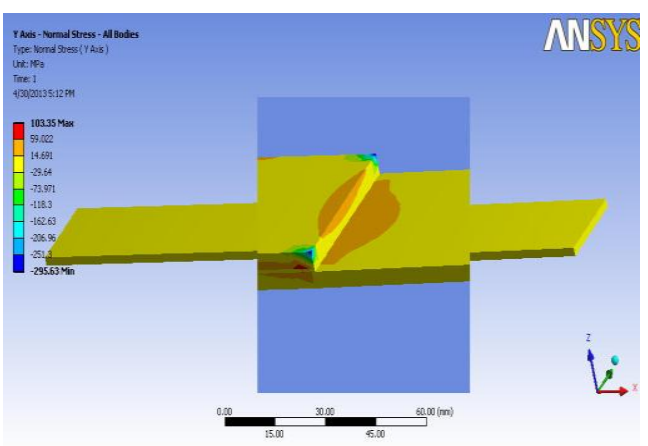

Fig 10: y axis normal stress

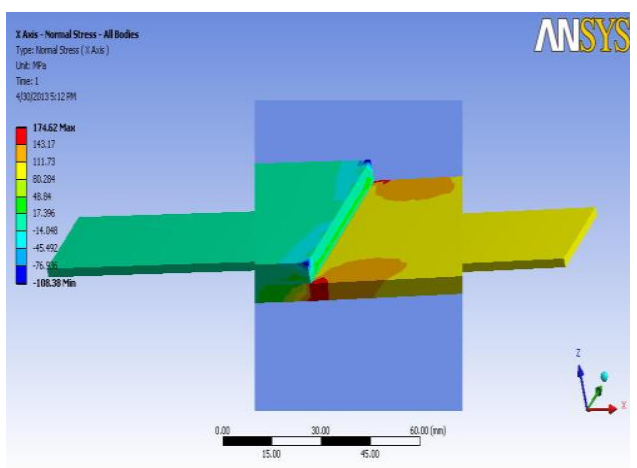

Fig 9: $\mathrm{x}$ axis normal stress

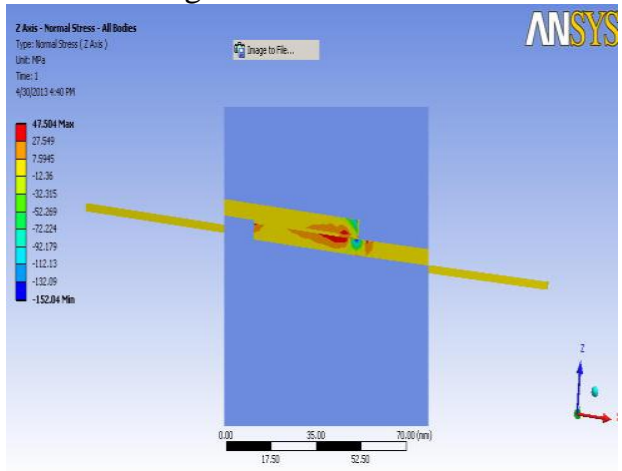

Fig 11: $\mathrm{z}$ axis normal stress

5.2 Riveted joints: The maximum value of vonmises stress for riveted joint is $443.66 \mathrm{~N} / \mathrm{mm}^{2}$ and the minimum value of stress is $0.00061223 \mathrm{~N} / \mathrm{mm}^{2}$. The rivet was meshed by using solid 45 , an 8 node brick element. The composite laminates were designed and meshed using hexagonal element. The minimum value of shear stress in GFRP was found to be $-157.83 \mathrm{~N} / \mathrm{mm}^{2}$ it was located on the laminates. The maximum value of the shear stress in GFRP was found to be $60.872 \mathrm{~N} / \mathrm{mm}^{2}$ it was located around the rivet head. The images of analysis result of vonmises stress, shear stress and normal stress of riveted joints are shown in the figure12-16.

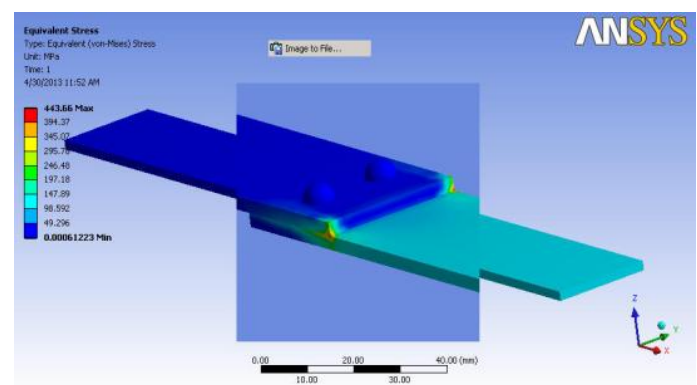

Fig12: Vonmises stress of riveted joint 


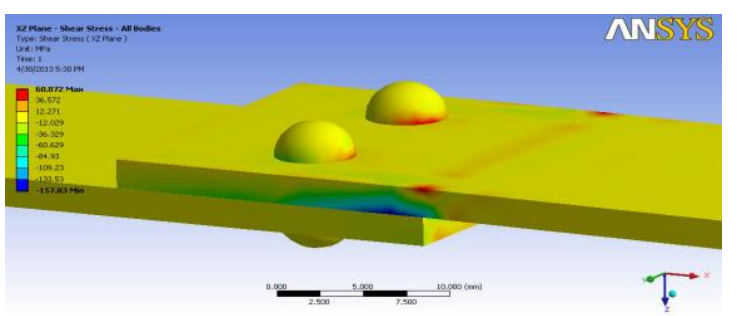

Fig 13: Shear stress

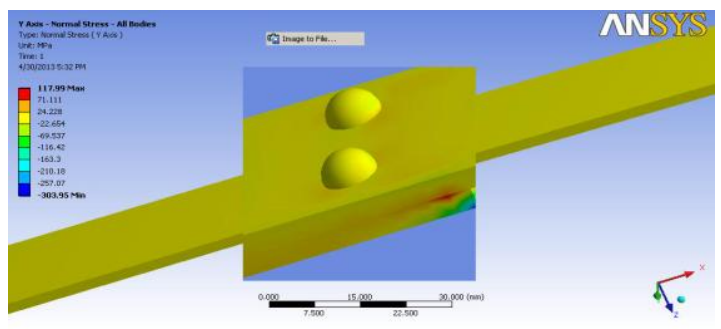

Fig 15: y axis normal stress

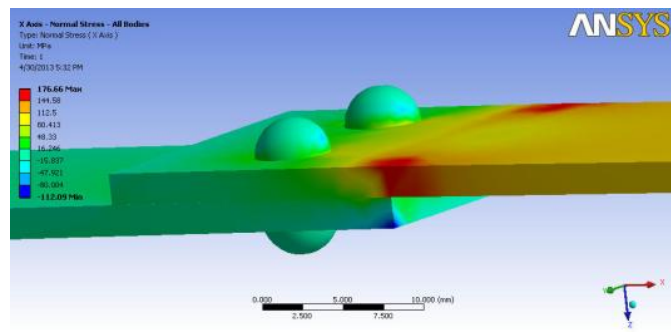

Fig 14: $\mathrm{x}$ axis normal stress

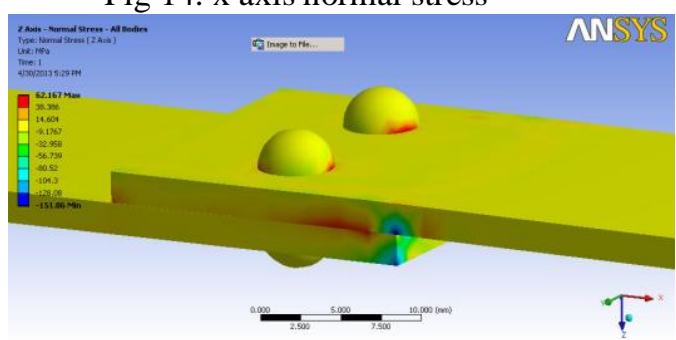

Fig 16: $\mathrm{z}$ axis normal stress

5.3 Hybrid joints: This model is similar to the riveted joint, excepts that it has a thin layer of adhesive between the laminates the minimum value of stress in GFRP was found to be $-154.33 \mathrm{~N} / \mathrm{mm}^{2}$ and was located on the laminates. The maximum value of stress in GFRP was found to be $59.029 \mathrm{~N} / \mathrm{mm}^{2}$ in the adhesive layer and rivet portion. The images of analysis result of vonmises, shear stress, normal stress of the hybrid joint are given in the fig17-21.

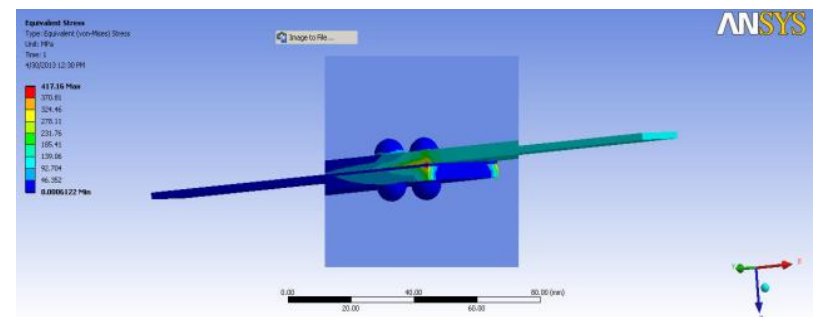

Fig17: vonmises stress of hybrid joint

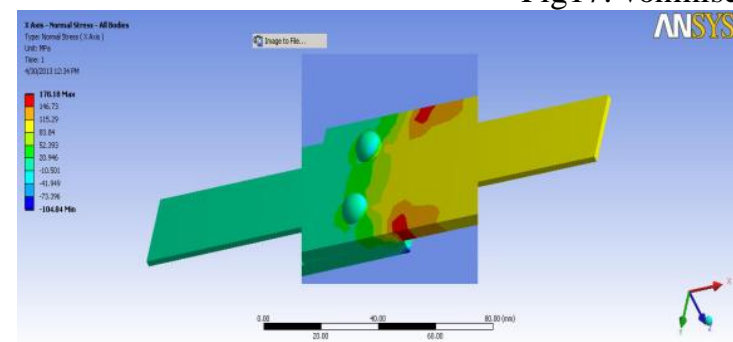

Fig18: $\mathrm{x}$ axis normal stress

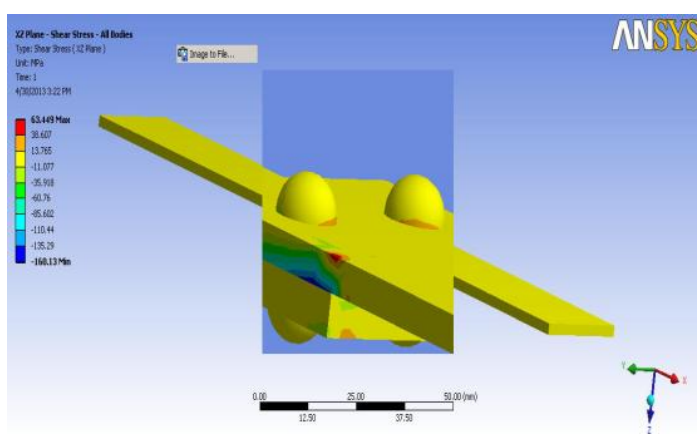

Fig 20: shear stress

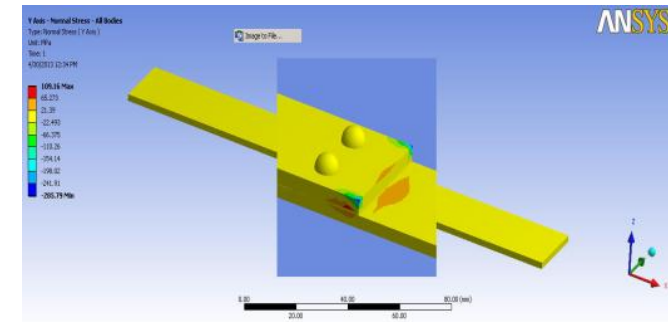

Fig19: y axis normal stress

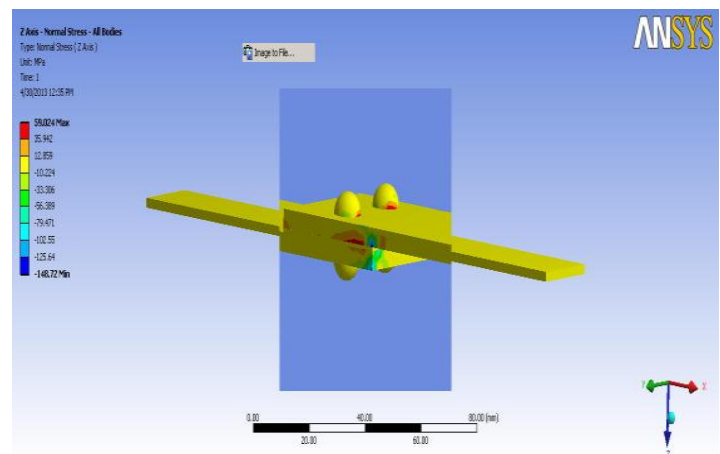

Fig 21: $\mathrm{z}$ axis normal stress

Comparison between bonded, riveted, hybrid joints. In bonded joints, the stress was distributed throughout the laminate and the adhesive took up much of the load. Since applying load acts on the joint, whereas in riveted 
joint, the rivet head and the laminate surface take up stress compared to the interior of the laminate and the rivet shank. The case of hybrid joint is found to have a situation that is the stress values are less when compared to bonded, riveted. So the hybrid joint is more efficient and also the hybrid joint with GFRP the cost is less. The values of vonmises stress, shear stress, and normal stress are referred in the Table (3) and graph (1) is shown below.

Table 4: stress values

\begin{tabular}{|c|c|c|c|c|c|}
\hline $\begin{array}{l}\text { Types of } \\
\text { joints }\end{array}$ & $\begin{array}{l}\text { Voamias } \\
\text { Strass } \\
\text { N/mm: }\end{array}$ & $\begin{array}{l}\text { Shear } \\
\text { Stress } \\
\text { N men: }\end{array}$ & $\begin{array}{l}\text { Nomal } \\
\text { stress in } \\
x \text { axis } \\
N / m m^{2}\end{array}$ & $\begin{array}{l}\text { Normal } \\
\text { stress in } \\
y \text { axis } \\
\text { N/min }\end{array}$ & $\begin{array}{c}\text { Nomal } \\
\text { stress in } \\
z \text { axis } \\
\mathrm{N} / \mathrm{mm}^{2}\end{array}$ \\
\hline bonded & 416 & 60.594 & 34 & 713.81 & 79 \\
\hline Riveted & 443.66 & 60.872 & 234.58 & 1606.7 & 32654 \\
\hline Hybrid & 417.16 & 59.029 & 6.082 & 398.37 & 95.47 \\
\hline
\end{tabular}

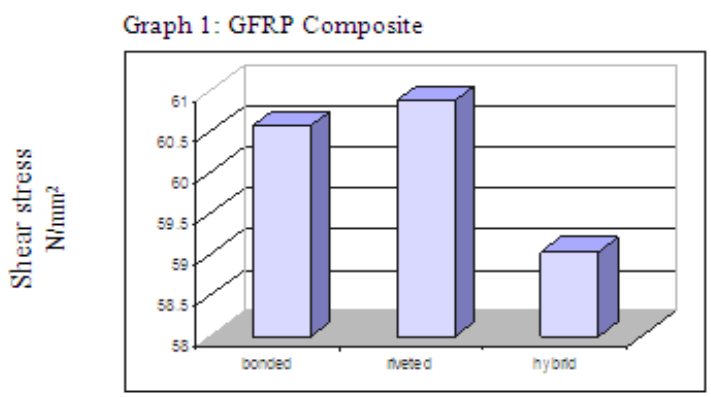

Types of joints

Graph 1: GFRP Composite

\section{Conclusion}

In this analysis, FEA for the prediction of stress distribution in bonded, riveted and hybrid joints have been carried out; 3-D models were created by using pro-E (creo parametric) and analyzed using ANSYS workbench FEA software. Shear stress was used to compare the results with three joining methods. The shear stress with hybrid joint has less value of stress and also the glass Fibre reinforced plastic material the cost is less than other composite material. The stress induced by using ansys is less than the material allowable stressIt was found that a well designed hybrid joint is very efficient when compared to bonded, riveted joints in case of repair situation in aircraft structures. The GFRP strength is less than that of the CFRP strength .

1. The same design can be made in experimental

\section{Scope Of Future Work}

2. GFRP with aluminium alloy plates can be tested in experimental

3. CFRP with aluminium alloy plates can be tested in experimental and can find the strength and stress distribution with different composite materials.

\section{References}

[1]. Noah M. Salih1, Mahesh J. Patil 2, Hybrid (Bonded/Bolted) Composite Single-Lap Joints And Its Load Transfer Analysis, International Journal of Advanced Engineering Technology E-ISSN 0976-3945 IJAET/Vol.III/Issue I/January-March, 2012/213-216.

[2]. Ch. Aswini Kumar1, G. Pattabhi2, S.Santosh3, I. Bhanu Latha4, Analysis of Adhesively Bonded Double Lap Joint in Laminated FRP Composites Subjected To Longitudinal Loading, international journal of engineering science \& advanced technology volume-2, issue-2, 307 - 316 ijesat | Mar-Apr 2012.

[3]. Vincentcaccesse, Richard newer, until s. vel detection of bolt load loss in hybrid composite.metalboltedconnectionselseiver engineering structures 26(2004) 895-906.

[4]. W. Hufenbach a, L.A. Dobrzański b, M. Gude a, J. Konieczny b, A. Czulak a, Optimisation of the rivet joints of the CFRP Compo site material and aluminum alloy, Journal of Achievements in Materials and Manufacturing Engineering, volume 20 issues 1 -2 JanuaryFebruary 2007.

[5]. M.A. McCarthy*, C.T. McCarthy, Finite Element Analysis Of The Effects Of clearance On Single-Shear, Composite Bolted Joints, Journal of Plastics, Rubber and Composites, The Institute of Materials, London, UK, Vol. 32, No. 2, in-press.

[6]. Proceedings of the "National Conference on Emerging Trends In Mechanical Engineering 2k13" 122 NCETIME - 2k13 Design Of Hybrid Composite Joints For Research Area S. Lokesha and H. Mohita a Student, Refrigeration and Air Conditioning Division, Department of Mechanical Engineering, College of Engineering, Anna University, Chennai-28. 